\title{
Arquitectura en el campo expandido. El concepto de Paisaje en los escritos y en la obra de Alejandro de la Sota
}

\author{
Mayka García Hípola ${ }^{1}$ \\ Recibido: 14-05-2019 en su versión final: 22-10-2020
}

Resumen

\begin{abstract}
Este artículo realiza un análisis de la obra y los escritos del arquitecto Alejandro de la Sota desde la óptica del paisaje, especialmente aplicando el concepto de campo expandido de Rosalind Krauss. El objetivo es explicar este concepto aplicado a su obra y extraer conclusiones de su importancia en el pensamiento y la producción de este arquitecto. Se ha elegido este arquitecto tan poco conocido internacionalmente para poder difundir y explicar su obra que ya ha sido explicada desde el punto de vista de la arquitectura, pero no tanto desde el del paisaje, excepto por algún artículo de NavarroBaldeweg. El método que se emplea consiste en el análisis de dos textos sobre paisaje (uno de 1952 y otro de 1954) y tres de sus obras (Guzmán, Maravillas y Alcudia). Como conclusión del estudio de casos, se deduce que la obra de este arquitecto supera lo arquitectónico y emplea el paisaje como elemento definidor y desencadenante de sus proyectos, consiguiendo que el proyecto salga del propio paisaje, en lugar de estar impuesto a él. Su obra es catalizadora del paisaje que rodea a sus proyectos; es decir, va más allá de la propia disciplina arquitectónica, expandiéndose hacia el paisajismo o la geografía, y abarcando de esta manera escalas que superan la arquitectónica, como la XL (territorial o geográfica) o la XS (de detalle o botánica). El artículo incorpora un diagrama final que, siguiendo el modelo de Krauss, propone un estudio de la obra de Sota desde la óptica del paisaje.
\end{abstract}

Palabras clave: Alcudia; Krauss; escala

Citación

\section{Architecture in the Expanded Field. The Concept of Landscape in the Writings and Work of Alejandro de la Sota}

Abstract

\begin{abstract}
This article makes an analysis of the work and writings of this architect, from the perspective of the landscape, especially applying the concept of the expanded field of Rosalind Krauss. Its objective is to explain this concept applied to his work and draw conclusions about its importance in the thinking and production of this architect. This architect, so little known internationally, has been chosen to be able to disseminate and explain his work, which has already been explained from the point of view of architecture, but not so much from that of the landscape, except for an article by Navarro-Baldeweg. The method used consists of the analysis of two texts on landscape (one from 1952 and another from 1954) and three works (Guzmán, Maravillas and Alcudia) by this architect. As a conclusion of the case study, it is deduced that the work of this architect surpasses the architectural and uses the passage as a defining element and trigger of his projects, getting the project to leave the landscape itself, instead of being imposed on it. His work is a catalyst for the landscape that surrounds his projects, architecture in the expanded field it goes beyond the architectural discipline itself towards other disciplines such as landscape or geography, thus encompassing scales that exceed architectural, such as the XL (territorial or geographical) or the XS (detailed or botanical). The article incorporates a final diagram that, following the Krauss model, proposes a study of Sota's work from the perspective of landscape.
\end{abstract}

Keywords: Alcudia; Krauss; scale

${ }^{1}$ Dra. Arquitecta. Profesora Titular, Escuela de Arquitectura, Universidad de Navarra (ORCID: $\underline{0000-}$ 0001-5411-0086, ResearcherID: B-4087-2017, Scopus Author ID: 55512603600). Correo de contacto: mghipola@post.harvard.edu

ACE, 15 (4.5) CC BY-ND 3.0 ES | UPC Barcelona, España | Arquitectura en el campo expandido. El concepto de 1 Paisaje en los escritos y en la obra de Alejandro de la Sota. DOI: http://dx.doi.org/10.5821/ace.15.45.8289 


\section{Introducción}

El concepto de paisaje que se estudia en este artículo no es solamente el correspondiente a la disciplina que trabaja el exterior de la arquitectura, sino que se considera también una estrategia que modifica la forma de proyectar arquitectura. A partir de la segunda mitad del siglo XX, este concepto ha evolucionado en paralelo al de arquitectura, actuando no solamente como su soporte exterior sino haciendo que ésta se situé más allá de sus tradicionales competencias. La valoración del este concepto y su empleo como elemento a investigar ha modificado el proyecto arquitectónico. Entre las consecuencias de esta evolución están el dialogo de la arquitectura con la cota cero del territorio y la aparición de nuevas cualidades espaciales asociadas a esta nueva relación entre disciplinas.

\subsection{Paisaje}

A lo largo de la historia, el paisaje ha sido usado y entendido de forma distinta por sus ocupantes o usuarios: desde sus primeras manipulaciones desde un punto de vista explotador o económico por parte de los agricultores, hasta otras posturas que lo consideraban como un elemento relacionado con la percepción meramente visual que acompañaba como fondo de la arquitectura. A partir del siglo XV y gracias a personajes como Petrarca (Maderuelo, 1996, Hofmann, 2007), el fondo comienza a adquirir sentido por sí mismo, sin necesidad de unas figuras o una arquitectura que le dé ese sentido. De la misma manera, la pintura del Quatrocento empezó a valorar no solo a los personajes sino al fondo de las representaciones, como ya venía haciendo con anterioridad el arte oriental. Si bien los lugares creados artificialmente por jardineros franceses (como Versalles) se basaban en una geometría abstracta, perfecta y ajena; los jardines ingleses (Gilpin, 1792; Price, 1794) se diseñaron más bien con una geometría propia de la naturaleza en la que trabajaban, valorando no solo los aspectos materiales del paisaje sino también los atmosféricos. Estos aspectos atmosféricos también aparecieron en la literatura de ese momento relacionada con el paisaje, como los textos de Flaubert, que incorporan descripciones paisajísticas próximas a la escala 1:1. Posteriormente, en el siglo XX, la aparición de nuevas cualidades como la entropía o la ecología han enriquecido el concepto de paisaje y la intensidad de su influencia sobre el proyecto arquitectónico (Smithson, 1973; Kwinter, 2002; Ábalos, 2005). Como se analiza a lo largo de este texto, los paisajes actuales vuelven a invertir la tradición occidental en el que se ha pasado de valorar los territorios por su belleza a valorarlos por otras cualidades además de la meramente visual.

Actualmente, el término paisaje alude no solo a la disciplina que se encarga del exterior de la arquitectura, sino que afecta a la forma en que es proyectada, su configuración interna, la relación con el suelo, los espacios internos e incluso a su piel. Hoy en día el paisaje ha ganado una importancia clave en el desarrollo de los proyectos, reforzando su relación con la arquitectura y formando un campo de fuerzas común, que es el que se estudia en este artículo.

\subsection{El concepto de "campo expandido" de Rosalind Krauss}

Rosalind Krauss, historiadora y crítica de arte estadounidense, emplea la definición de campo expandido para estudiar el acercamiento de la escultura hacia otras disciplinas como la arquitectura o el paisaje. Este texto toma prestado su título del artículo "Escultura en el campo expandido" (Krauss, 1981). Esta autora también escribió otro texto titulado "Doble negativo, una nueva sintaxis para la escultura” (Krauss, 1979). Ambos hacen uso de la útil estrategia de la negación para buscar nuevas posibilidades para las disciplinas artísticas.

ACE, 15 (4.5) CC BY-ND 3.0 ES | UPC Barcelona, España | Arquitectura en el campo expandido. El concepto de 
Krauss propone un criticismo que valora el método más que el contenido y el descubrimiento de nuevas estrategias más que la corroboración histórica de éstas. Esto, en contra de lo que, según ella, hacía Clement Greenberg (Kimball, 1987), a quien tacha de historicista. Aunque valora el trabajo de Greenberg, presentado entre los años 60-65 en la revista Art Culture por su sistema a través del cual analizar arte, Krauss considera que la crítica debería ser menos anacrónica y propone una renovación de las formas trans-históricas. Considera el postmodernismo como un cambio radical, una ruptura de límites en la manera de entender el arte del siglo XX, de una manera no historicista. En una época en la que el mundo tenía su centro artístico en Nueva York, ciertos críticos como ella se dejaron influir por corrientes que venían del extranjero como la semiología, el estructuralismo o el postestructuralismo, utilizando sus herramientas para revelar nuevas actitudes en las artes visuales. Esta apertura de la crítica al exterior y su contaminación tiene lugar al mismo tiempo que las distintas doctrinas artísticas rompen sus límites dejándose contaminar mutuamente, desdibujando sus encorsetadas barreras y evitando la hegemonía de unas doctrinas sobre otras, como defendía Greenberg, quien colocaba la pintura muy por encima de cualquier otra disciplina artística.

En los artículos mencionados anteriormente, Krauss analiza la relación entre pares antagónicos, utilizando la estrategia de la negación. La estrategia de la negación busca un tercer término, término intersticial entre los tradicionales binomios como pueden ser: innovador-tradicional, natural-artificial, arquitectura-paisaje, figura-fondo, edificio-territorio, interior-exterior, construido-no construido, dentro-fuera, lleno-vacío. Este tipo de actitud desmonta las tradicionales oposiciones binarias de la cultura occidental. Para ello, esta autora utiliza herramientas relacionadas con la negación importadas del campo de las matemáticas, como el Diagrama de Klein, para proponer nuevos términos doctrinales obtenidos mediante la negación de los tradicionales (arquitectura/paisaje, noarquitectura/no-paisaje), y propone el entendimiento de esta relación desde una nueva sintaxis extendida. Se usa la negación para crear un diagrama donde las nuevas tendencias en escultura se sitúan en el campo extendido de otras doctrinas. El concepto de "campo expandido" de Krauss es una negación en sí mismo porque la escultura puede ser una cosa y su opuesto, así como dos negaciones al mismo tiempo (no-arquitectura y no-paisaje). Se valora el concepto de negación frente al de oposición.

Como se va a analizar a lo largo de este artículo, Alejandro de la Sota (cuya obra es contemporánea a la de Krauss) también hace uso en su obra de estos términos intersticiales, así como Aldo Van Eyck, quien también apostó por la devaluación de las dualidades antagónicas y la reconciliación de opuestos. Van Eyck afirmaba que el territorio del hombre es un territorio de en medio, abogando por lo que tiene la escala oportuna, lo que es a la vez grande y pequeño, poco y mucho, cerca y lejos, simple y complejo, abierto y cerrado, parte y todo, unidad y diversidad. En su texto titulado "En el interior del tiempo", Van Eyck (1990) revela que lo que debería ocurrir es que se trastocase la existente categoría de arquitecto-urbanista para así acabar con las dualidades "fuera-dentro" y todas las dualidades antagónicas que él llama fenómenos gemelos (twinphenomena). Esto, ya que en su caso supone y propone la reconciliación de esas dos dualidades. La idea de fenómeno gemelo, o dual, tiene sentido positivo, no negativo.

De la misma forma que Krauss explica cómo la escultura ha sido "estirada" a lo largo de la postmodernidad, al paisaje y a la arquitectura de las últimas décadas le ha pasado algo similar. Se puede considerar al arquitecto español Alejandro de la Sota uno de los pioneros de esta tendencia en España, que ha acercado la arquitectura a otras disciplinas como la geografía (a escala macroscópica) y la geología (a escala microscópica), más próximas al paisaje. Anthony Vidler manifiesta que en la "geología post-histórica, la única constante es la naturaleza sistemática del azar, una cualidad bien conocida en las matemáticas de la topología y topografía, pero menos en arquitectura" (Vidler, 1988), aunque bastante en el paisaje, como se verá a lo largo de este capítulo.

ACE, 15 (4.5) CC BY-ND 3.0 ES | UPC Barcelona, España | Arquitectura en el campo expandido. El concepto de 3 Paisaje en los escritos y en la obra de Alejandro de la Sota. DOI: http://dx.doi.org/10.5821/ace.15.45.8289 


\subsection{Cota cero}

Dentro del concepto del campo expandido en fundamental la idea de la cota cero porque como la propia Krauss explica, todo sucede por debajo y por encima de esa línea. El texto "Escultura en el campo expandido" (Krauss, 1981) comienza con una fotografía de la obra de Mary Miss titulada Perimeter/Pavilions/Decoys realizada en 1978 en Condado de Nassau, Long Island, Nueva York. Krauss define este trabajo como algo que está completamente por debajo del nivel del suelo, en la cota cero del terreno, y lo utiliza como ejemplo de cómo el término escultura ha sido "estirado" a través de las prácticas de vanguardia. A pesar de ir contra el comentado criticismo historicista de Greenberg, Krauss presenta referencias históricas para este tipo de proyectos donde se involucra la cota cero del terreno, como son Stonehenge, las líneas de Nazca, los patios de pelota aztecas, los laberintos, los enterramientos indios, los jardines japoneses e incluso el primitivo trabajo de Brancusi. Todas estas obras tienen en común su fuerte vínculo con el suelo.

La ground line (línea de suelo, cota 0 o línea fluctuante horizontal) ha sido hasta ahora una barrera. Muchos son los proyectos arquitectónicos de los últimos años que la traspasan y llevan al límite las ideas de anclaje en el lugar (Figura 1). Steven Holl declara en su libro Anchoring (anclaje) que la arquitectura no se impone a un lugar, sino que más bien sirve para explicarlo (Holl, 1989), y podría añadirse que para entenderlo. Para Peter Eisenman, el paisaje es el modo de ser anti-espectacular en arquitectura (Eisenman, 2008). Rem Koolhaas, en su memoria para el concurso del Illinois Institute of Technology (ITT), dijo que la arquitectura ya no es el elemento primario del orden urbano, sino que, de una manera creciente, el orden urbano viene dado por un fino plano vegetal horizontal; de manera creciente, el paisaje es el elemento primordial del orden urbano, involucrando de esta forma al paisaje en la ciudad (Koolhaas, 1998) y a la cota cero de esta.

Figura 1. Ideogramas realizados por la autora de diferentes proyectos de Peter Eisenman, MVRDV y Rem Koolhaas

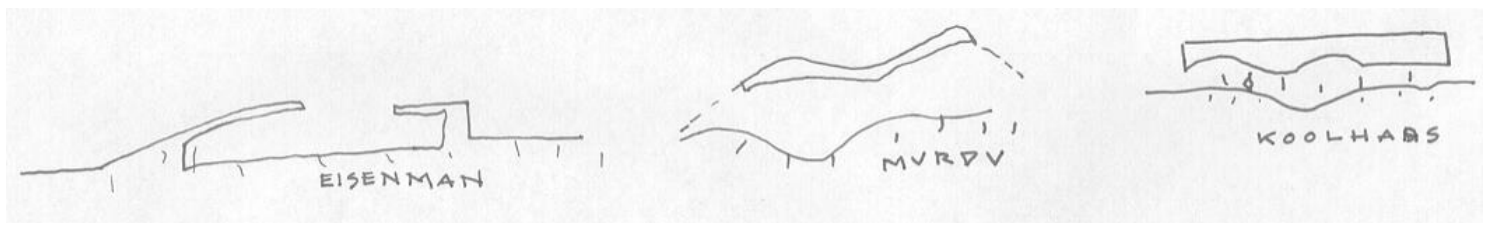

Fuente: García Hípola, Mayka.

Los arquitectos se sienten seducidos por el poder de esa cota cero. Esta capacidad de seducción se produjo primero en el campo del arte y luego en el de la arquitectura, que necesita un lapso mayor de tiempo para su aplicación, como pasó con las vanguardias de inicio del siglo XX (el cubismo de los años veinte no influyó en la arquitectura del modernismo hasta la década de los 50). Asimismo, el Land Art aparece en el campo artístico a finales de los años 60 en Estados Unidos, coincidiendo con la exposición "Arquitectura sin arquitectos" (Rudofsky, 1964) organizada por el Museum of Modern Art (MOMA), en donde se exponían trabajos primitivos con un fuerte vínculo con la cota cero. Ese vínculo con la cota cero del terreno también se da en la obra de Alejandro de la Sota, como veremos en su obra para el Gimnasio Maravillas o la Casa Guzmán, al igual que en sus textos. Su obra se presenta como una oportunidad de abrir la arquitectura hacia otras disciplinas como el paisaje, como hizo Krauss con la escultura en el texto "Doble negativo, una nueva sintaxis para la escultura" (Krauss, 1979). Por tanto, la metodología que se emplea consiste en el análisis de dos textos de De la Sota sobre paisaje (uno de 1952 y otro de 1954) y tres de sus proyectos arquitectónicos (Guzmán, Maravillas y Alcudia), para analizar si su obra supera lo arquitectónico y emplea el paisaje como elemento definidor y desencadenante de sus proyectos, consiguiendo que el proyecto salga del propio paisaje, en lugar de estar impuesto a él. Ésta es la razón particular por la que se decide aplicar la idea de campo expandido a la obra de De la Sota.

ACE, 15 (4.5) CC BY-ND 3.0 ES | UPC Barcelona, España | Arquitectura en el campo expandido. El concepto de

Paisaje en los escritos y en la obra de Alejandro de la Sota. DOI: $\underline{\text { http://dx.doi.org/10.5821/ace.15.45.8289 }}$ 
El Diagrama de Krauss comentado al inicio de este artículo pone en relación lo binomios antagónicos de paisaje y arquitectura, proporcionando un campo expandido de posibilidades más allá de campo doctrinal de estas disciplinas.

\section{Paisaje en la obra de Alejandro de la Sota}

Utilizando el concepto de campo expandido de Rosalind Krauss para esta nueva relación y definición del concepto del paisaje, se analizan en este artículo distintas obras escritas, construidas y proyectadas por Alejandro de la Sota. El autor habla de la importancia del paisaje y su escala en sus textos y lo materializa en sus proyectos.

En este artículo se estudian los textos "Algo sobre paisajes y jardines" (De la Sota, 1952) y "La arquitectura y el paisaje” (De la Sota, 1954)1. Asimismo, las obras arquitectónicas estudiadas son el Gimnasio Maravillas de 1962, la Casa Guzmán de 1972 y las Viviendas en Alcudia de 1984, como caso de estudio principal. La elección de estas obras se ha hecho teniendo en cuenta que son las que mejor materializan los conceptos desarrollados en los artículos escritos por De la Sota, por su fuerte vinculación con el suelo o cota cero del territorio y por tratarse de arquitecturas en el campo expandido; es decir, aquellas que amplían la obra arquitectónica más allá de sus límites doctrinales.

En relación con la doctrina del paisaje, el bagaje cultural y artístico de Alejandro de la Sota es amplio. En sus textos, De la Sota analiza su relación con la obra de otros artistas como Cezanne, Neutra, Burle Marx, Mies, Asplund o Wright, así como con otros constructores, como los ingenieros o incluso los animales, defendiendo una especie de "arquitectura sin arquitectos" -en la línea de Bernard Rudofsky (Rudofsky, 1964)- o también una "arquitectura en el campo expandido" (Krauss, 1979). A manera de aclaración, los textos de Alejandro de la Sota analizados en este artículo preceden a las obras de Rudofsky o Krauss en el estudio del paisaje, la arquitectura y su relación, lo que nos da una idea de la importancia de explorar la obra de De la Sota como literatura fundamental en esta disciplina.

\subsection{Textos}

El texto titulado "La arquitectura y el paisaje" (De la Sota, 1952) es el más próximo a la idea de campo expandido de Krauss descrita anteriormente. En él, se da una definición de paisaje de la Real Academia que expone que paisaje "es una porción de terreno considerado en un sentido artístico" (De la Sota, 1952, p. 28), implicando que con esta noción de paisaje se quiere ir más allá de los límites físicos del concepto y de los conceptuales de la disciplina. De la Sota añade que esta definición no detalla si en esa porción de terreno tiene que haber o no edificación. Por ello, denomina a este último, paisaje rústico, y al primero, urbano. Asimismo, destaca que se pueden obtener paisajes mixtos compuestos por una mezcla de ambos.

De la Sota añade que el hombre disfruta construyendo paisajes y destaca cómo antiguamente se actuaba sobre el paisaje sin perjudicarlo. La forma era dada por los materiales que eran similares o iguales a los de la naturaleza alrededor de ellos, una arquitectura mimética que siempre es "una buena regla” (De la Sota, 1952, p. 29). De la Sota apunta a cómo contemplamos hoy en día el paisaje, desde una carretera, mientras vamos en el coche y circulamos en medio de un trazado dibujado en medio de lo virgen. Y aunque él no lo afirma, seguramente realizada por un ingeniero anónimo. De la Sota habla de puentes, caminos y muros de contención, todas ellas obras de ingeniería.

\footnotetext{
${ }^{1}$ Aunque también existe un texto titulado "Arquitectura y Naturaleza” (De la Sota, 1956), esta investigación se centra en los dos textos de 1952 y 1954 por ser los que más inciden en la relación entre arquitectura y paisaje dentro del campo expandido de estas disciplinas.
}

ACE, 15 (4.5) CC BY-ND 3.0 ES | UPC Barcelona, España | Arquitectura en el campo expandido. El concepto de

Paisaje en los escritos y en la obra de Alejandro de la Sota. DOI: http://dx.doi.org/10.5821/ace.15.45.8289 
Sobre el tema de la decoración en los puentes, De la Sota sostiene que son obras que deben tener huesos hermosos y no se valoran por su carne y menos aún por sus trajes. Por otro lado, cita a Paul Bonatz, arquitecto que según De la Sota trabaja más allá de la arquitectura, siendo que en Alemania fueron muy cuidadosos con la tierra removida para hacer carreteras: después de mantenerla en los depósitos apropiados para mantener sus propiedades fértiles, se extendió cuidadosamente a lo largo de las laderas de las carreteras adyacentes. Luego de unos meses, el camino se transformó en una alfombra extendida en un paisaje inmaculado, demostrando mediante estos ejemplos su actitud respetuosa frente a la acción arquitectónica sobre el territorio.

De la Sota menciona también a Gabino Lagarriga, quien le dijo: "¿Por qué no dejan que los campesinos construyan sus casas? ¿No construyeron la alondra y el castor?" (De la Sota, 1952, 30). Como haría posteriormente Rudofsky en el libro "Arquitectura sin arquitectos" (Rudofsky, 1964) De la Sota alude y defiende este tipo de arquitectura, no de arquitectos, sino del ingeniero anónimo o del animal que se autoconstruye su hábitat. También menciona que a veces los hombres viven en cuevas y hace referencia a un pueblo llamado Dueñas, donde Ortega y Gasset manifiesta que los hombres viven como hormigas.

Posteriormente, en "Algo sobre paisajes y jardines" De la Sota (1954) introduce la idea escalar al equiparar los conceptos de paisaje grande o paisaje pequeño. "Es labor de artistas descubrir lo bueno de cada paisaje. Quiero decir que, cuando de crear paisaje se trate, paisaje grande o pequeño [...], es necesario usar solo lo que nos quedó en el tamiz" (De la Sota, 1954, p. 31). A la hora de trabajar con ellos, hay que trabajar de la misma forma, partiendo de lo esencial. Para crear un paisaje lo primero que hay que hacer, según De la Sota, es condensarlo, lo que se entiende -en esta investigación- como una idea más escalar que dimensional (García-Hípola, 2014), por su referencia a la proporción en lugar de al tamaño. Esto es algo que también se analiza más adelante en el caso de las viviendas en Alcudia, donde se relaciona el pequeño patio de las viviendas con la grandeza del territorio circundante. De la Sota insiste en que, a pesar del pequeño tamaño de estos jardines, pueden abarcar la gran escala del paisaje. Hace referencia a cómo el jardín japonés está compuesto solamente por un charco, dos piedras, dos bambúes. Todo el jardín mide tan solo 2 metros cuadrados, más, sin embargo, cuando lo contemplamos "el corazón se hace más grande" (De la Sota, 1954).

De la Sota pide en "Algo sobre paisajes y jardines" que no se repita Versalles, defendiendo que la naturaleza ha de ser tratada de un modo natural y hace alusión a la materialidad propia de cada paisaje: la hierba al norte y la arena al sur. Como se veía en la introducción al concepto de paisaje, De la Sota está más interesado en las cualidades no tangibles del paisaje y no en la ópticas o visuales propias de estos jardines franceses. Alude a cómo los pintores impresionistas se centraban en raíces en lugar de las ramas, en la savia en lugar de en los frutos, "labrando materialmente surcos en la gorda pintura color tierra” (De la Sota, 1954, p. 31). Avisa que el paisaje es el mismo, pero somos nosotros los que cambiamos, dando, sin decirlo expresamente, una gran importancia a la figura del usuario o espectador.

\subsection{Proyectos}

Los proyectos analizados en este artículo son según la definición explicada anteriormente: urbano (Maravillas), rústico (Guzmán) y mixto (Alcudia), abarcando cada uno de ellos distintas escalas de este concepto: paisaje urbano, paisaje rústico y paisaje mixto: $\mathrm{XL}, \mathrm{L}, \mathrm{M}$ y S, como se analiza a lo largo de este artículo.

Lo que De la Sota analiza y cuestiona en estos textos del punto 2.1 (la arquitectura mimética con el paisaje circundante, la arquitectura anónima, el campo expandido, el suelo, la escala, los materiales) lo materializa en sus obras construidas. Trabaja en algunos de sus proyectos con la escala XL, como

ACE, 15 (4.5) CC BY-ND 3.0 ES | UPC Barcelona, España | Arquitectura en el campo expandido. El concepto de 6 Paisaje en los escritos y en la obra de Alejandro de la Sota. DOI: http://dx.doi.org/10.5821/ace.15.45.8289 
un estratega territorial, cercano al ingeniero que mencionaba en sus textos. En otros, sin embargo, proyecta desde la escala S, más propia del jardinero o del carpintero. Algunas obras de este creador integral trabajan con la escala urbana, cuestionando incluso lo arquitectónico, como pasa con el Gimnasio Maravillas, un proyecto encargado a De la Sota para realizar un polideportivo en un colegio existente en un solar con una gran pendiente.

\subsection{El Gimnasio Maravillas}

De la Sota expone en la memoria de este proyecto, construido en Madrid en 1962, que el edificio nació como quería (Baldellou, 1997 y Couceiro, 2007). Estaban preocupados por problemas urbanos, la explotación económica productiva del solar, lo que los llevó a no estar preocupados por una cierta arquitectura. De la Sota concluye que explicarlo llevaría a la polémica de "arquitectura si, arquitectura no" que coincide con la estrategia de negación explicada en los textos de Krauss. Entonces el gran problema fue solucionado y destaca cómo hoy en día continúa funcionando. "Nadie echa en falta la arquitectura que no tiene". (Couceiro, 2007, 43). Esta cita ayudar a establecer muchas relaciones con lo expuesto sobre el "campo expandido" de Krauss y la estrategia de la negación, ya que se trata tanto la arquitectura como la arquitectura, el paisaje y el no paisaje. No está claro si es un edificio o una actuación paisajística urbana, pero no importa, porque funciona y sigue funcionando cuando ya han pasado casi 60 años de su construcción. Fue una gran idea aprovechar la diferencia de cota para la construcción del gimnasio. Parecía la única solución posible para ese lugar, un gran y único edificio con una fuerte luz lateral, afortunadamente proveniente del sur. En sus dibujos, el sol y el aire cobran tanta importancia como los elementos urbanos o constructivos (Figura 2). Disciplinas como la topografía dieron lugar a esta obra, como desencadenantes proyectuales, llevando a la arquitectura más allá de sus límites doctrinales.

Figura 2. Sección del Gimnasio Maravillas

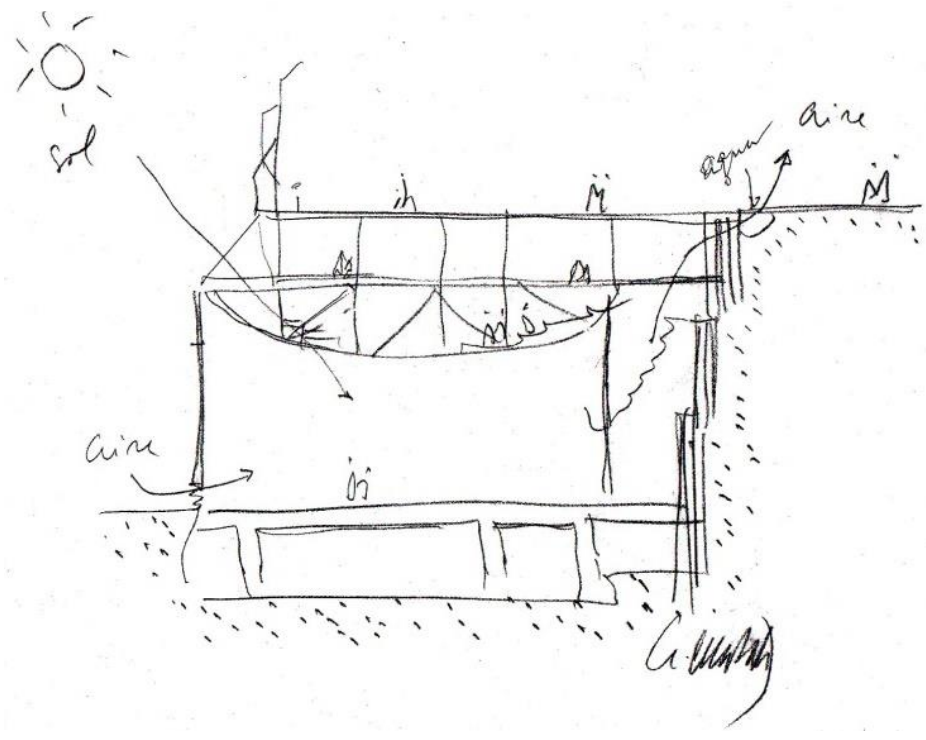

Fuente: Archivo de la Fundación Alejandro de la Sota.

Podría decirse que es este edificio es arquitectura "en campo expandido" siguiendo la denominación de Rosalind Krauss sobre la relación entre arquitectura y paisaje y no-arquitectura y no-paisaje. "Se habló de la arquitectura en el paisaje, y podría volverse la oración pasiva, empezando nuevamente por el paisaje en la arquitectura" (De la Sota, 1952). De esta forma estas obras se encuentran entre el paisaje y la arquitectura y está relacionadas con la cota cero, que en este artículo está representadas por el gimnasio Maravillas.

ACE, 15 (4.5) CC BY-ND 3.0 ES | UPC Barcelona, España | Arquitectura en el campo expandido. El concepto de 7 Paisaje en los escritos y en la obra de Alejandro de la Sota. DOI: $\underline{\text { http://dx.doi.org/10.5821/ace.15.45.8289 }}$ 


\subsection{La casa Guzmán}

Otras obras de De la Sota son de escala S, pero el arquitecto las amplia más allá de sus muros, formando parte de su campo expandido, como sucede en la Casa Guzmán, que supera la escala arquitectónica. Esta obra quería, como se afirma en su memoria, ser una casa "de campo", superando con esta denominación territorial el carácter arquitectónico de "chalet" u "hotelito", propio de las obras que lo rodeaban. El arquitecto español apunta que las palabras "pequeños hoteles" o "chalets" son aquellas terribles expresiones que han contribuido a las casas kitsch que aparecen en la proximidad de las grandes ciudades ${ }^{2}$. Situada entre la carretera y el río Jarama, el lado noroeste de la casa Guzmán se abre como una cornisa al paisaje, en la que De la Sota construyó una cascada de terrazas que juegan con las cotas existentes: 2.20, 1.65, 2.60, 3,10, 0.00 metros. "Hay que dejar que la casa flote, suba y baje, y quede en su cota. La casa es un sólido flotando en magma y ella sola fijara su cota. Es precioso ser el observador del sube y baja hasta el edificio final. ¡Gracias casa!" (De la Sota, 1952, p. 28).

En la casa Guzmán se produce un interesante contraste entre el techo material y el techo textil, producido por los toldos que se apoyan en una estructura de líneas continuas que, como las barandillas, son curvas sin esquinas, y parecen provenir de la geometría de la naturaleza existente de su campo expandido. Los cerramientos fijos de ladrillo y revestimiento de plaqueta contrastan con los cerramientos móviles que, a modo de celosía metálica, conforman espacios que son variables y móviles según las distintas estaciones del año. Debido al buen tiempo en primavera, verano y otoño, la zona de estar es muy abierta hacia el exterior. Es una casa abierta pero que puede ser cerrada. Siguiendo las ideas de Krauss se puede decir que esta obra está entre la arquitectura y la noarquitectura porque tiene que ver con lo industrial y con la construcción.

En el primer texto analizado en este artículo se habla además de las cosas enunciadas anteriormente del uso de la cal (De la Sota, 1952). El hombre primero la empleó dentro de sus casas y más tarde en el paisaje, llenando todo con "la felicidad suministrada por el color blanco" (De la Sota, 1952, p. 31), huyendo del mimetismo anteriormente mencionado. Pero tampoco niega el valor de los trasplantes arquitectónicos. El uso de los cerramientos metálicos en la casa Guzmán tiene que ver con esos injertos o trasplantes, la artesanía cerámica contrasta con la industrialización metálica, lo fijo con lo móvil, el dominio con el recogimiento. Los cerramientos metálicos móviles permiten "estar dentro de tu casa y que en ella penetre el jardín, que no pises raya al pasar sobre este dentro-fuera” (De la Sota, 1952, 28) y comenta “iVer Castilla desde el interior de nuestras casas! ¿Qué mejor jardín?” (De la Sota, 1952, p. 28). En esta casa se ponen en práctica estrategias constructivas que luego volverán a aparecer en Alcudia.

Otros autores han analizado la obra de la De la Sota desde el punto de vista de la arquitectura (Puente, 2002, Ábalos et al., 2009, Baldellou, 1976, 2006), pero solamente Juan Navarro-Baldeweg lo hace desde el paisaje. En su discurso pronunciado en la Real Academia, Navarro (2003) aporta conceptos que podían ser aplicables a esta casa (al igual que a las viviendas en Alcudia) como la "habitación de la vista”, donde lo físico se inscribe en el horizonte visual. En la casa Guzmán ocurre algo similar a las del arquitecto americano Richard Neutra, contemporáneo de De la Sota y cuya visita a España influyó en los arquitectos del momento. De la Sota quedó tan impresionado por cómo la obra de Neutra dialogaba con el paisaje, que incluyó algunas apreciaciones específicas en sus textos de 1952 y 1954. Tanto en las casas de De la Sota como en las de Neutra (Figura 3), se trabaja con conceptos como el horizonte y el campo óptico. Ambos conceptos proporcionan emoción espacial producida por la

2 La demolición reciente de la Casa Guzmán y la construcción de una nueva vivienda ha hecho que tristemente esta obra se haya convertido en una más propia de otro momento y lugar geográfico, que desde luego ya no es una "casa de campo". La "casa de campo" según Sota, podía ser heredada o proyectada de nueva planta. En 2017 la casa Guzmán fue heredada y sus herederos la convirtieron en el criticado "chalé" u "hotelito" que desde el principio no quiso ser.

ACE, 15 (4.5) CC BY-ND 3.0 ES | UPC Barcelona, España | Arquitectura en el campo expandido. El concepto de

Paisaje en los escritos y en la obra de Alejandro de la Sota. DOI: http://dx.doi.org/10.5821/ace.15.45.8289 
habitación de la vista, un concepto visual que se relaciona con la habitación como hecho físico. Al combinarse ambas crean el espacio arquitectónico, que se ve ampliado en estos casos por la ausencia de estructura o carpintería en la esquina del diedro. Este juego entre la escala $L$ (del territorio) y la $S$ (de la habitación) vuelven a encontrarse en el magnífico paisaje integral que conforman sus viviendas en Alcudia, otro gran ejemplo de arquitectura en el campo expandido.

Figura 3. Comparación entre imágenes de la Casa Guzmán a la izquierda y las casas de Richard Neutra Hinds (1951) en medio y Moore (1950) a la derecha
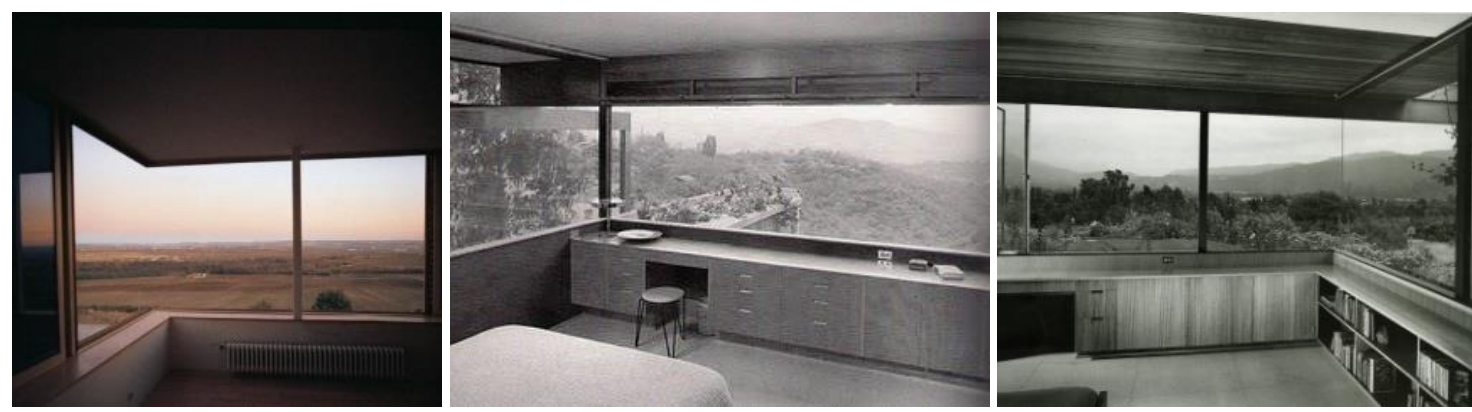

Fuente: Elaboración propia.

\subsection{Las viviendas de Alcudia}

La idea de Krauss de "campo expandido" se refleja en estas viviendas de manera especial. El uso que se hace de la cota cero en relación con el paisaje topográficamente abrupto en magistral. Además, la arquitectura propuesta enmarca el paisaje y el horizonte existente y el paisaje también enmarca la arquitectura. La idea de horizonte rememora la imagen de un vasto recinto, al igual que la ubicación del proyecto de las viviendas de Alcudia realizado en Mallorca en 1984 (Gallego, 2004 y MartínezArroyo, 2006). El proyecto es un lugar de existencia definido en el interior de un sinnúmero de fugas visuales que constituyen e integran el espacio (Navarro-Baldeweg, 1997) (en este caso hacia el mar y la montaña). Para Navarro, cualquier objeto o la pared de la habitación son obstáculos en el fluir libre de la vista desde ese centro. Lo que se describe en este texto podría aplicarse a la experiencia que tendríamos si estas viviendas se hubiesen construido y las pudiésemos visitar, como en la Casa Guzmán, analizada anteriormente. Para Navarro, existe un conjunto de circunscripciones definidas por los bordes de la vista que definen el primer plano, plano medio y plano largo que son planos que también se pueden detectar en las viviendas de Alcudia como se puede ver en el dibujo adjunto (Figura 6). En estas viviendas, los planos podrían ser la habitación (primer plano), el patio (plano medio), y el territorio (plano lejano) (Figura 5). "La posibilidad de vagar o saltar en los distintos horizontes convocados, ese volumen capaz comprende en su interior todas las miradas particulares, los recorridos visuales, el conjunto de las instantáneas, formadas por fibrillas particulares de ese otro cuerpo universal acumulativo" (Navarro-Baldeweg, 1997, p. 36). Ese marco acumulativo que menciona Navarro podría relacionarse con la percepción múltiple que se tendría al habitar las estancias de estas viviendas. La visión de la realidad es múltiple y como declara Navarro al desplazarse la mirada, el paisaje se desdobla, multiplicándose en innumerables visiones y se despliega en fondos que abarcan lo próximo y lo lejano. En este proyecto los fondos podrían ser el paisaje interno del patio-próximo y el externo del territorio-lejano. Según Navarro, el ojo se multiplica en innumerables ojos. La vista se proyecta en el espacio y también habita en el tiempo. La línea del horizonte o ese velo descrito como integral de líneas entrecruzadas dan pie a una superficie ondulante, como el muro de una última habitación. En estas viviendas la vista se multiplica de nuevo en diversas visiones percibidas, desde la habitación arquitectónica a la habitación del horizonte.

ACE, 15 (4.5) CC BY-ND 3.0 ES | UPC Barcelona, España | Arquitectura en el campo expandido. El concepto de

Paisaje en los escritos y en la obra de Alejandro de la Sota. DOI: http://dx.doi.org/10.5821/ace.15.45.8289 
Por otra parte, este proyecto de Alcudia añade otro tema singular en la obra de De la Sota en relación con el paisaje, como es el urbanismo. En el primer texto analizado en este artículo, De la Sota (1952) expone que "saber cómo lograr esta mezcla entre paisaje y ciudad significaría entender un nuevo urbanismo urbano que nos permita vivir una vida mejor, con un contacto más fuerte con la naturaleza". Cita, además, una frase cómica atribuida a Lenin: "iqué sano es el campo, edifiquemos allí nuestras ciudades" (De la Sota, 1952, p. 28). Para De la Sota, la idea de combinar estas dos disciplinas llevó al pueblo árabe a construir maravillas. De la Sota decía bajo la imagen del litoral que publicó en 1952 (Figura 4): “iRealmente, no hay derecho, ni disculpa!”, refiriéndose al exceso de construcción que se ha dado en el litoral español en la segunda mitad del siglo XX

Figura 4. Imagen de "La arquitectura y el paisaje"

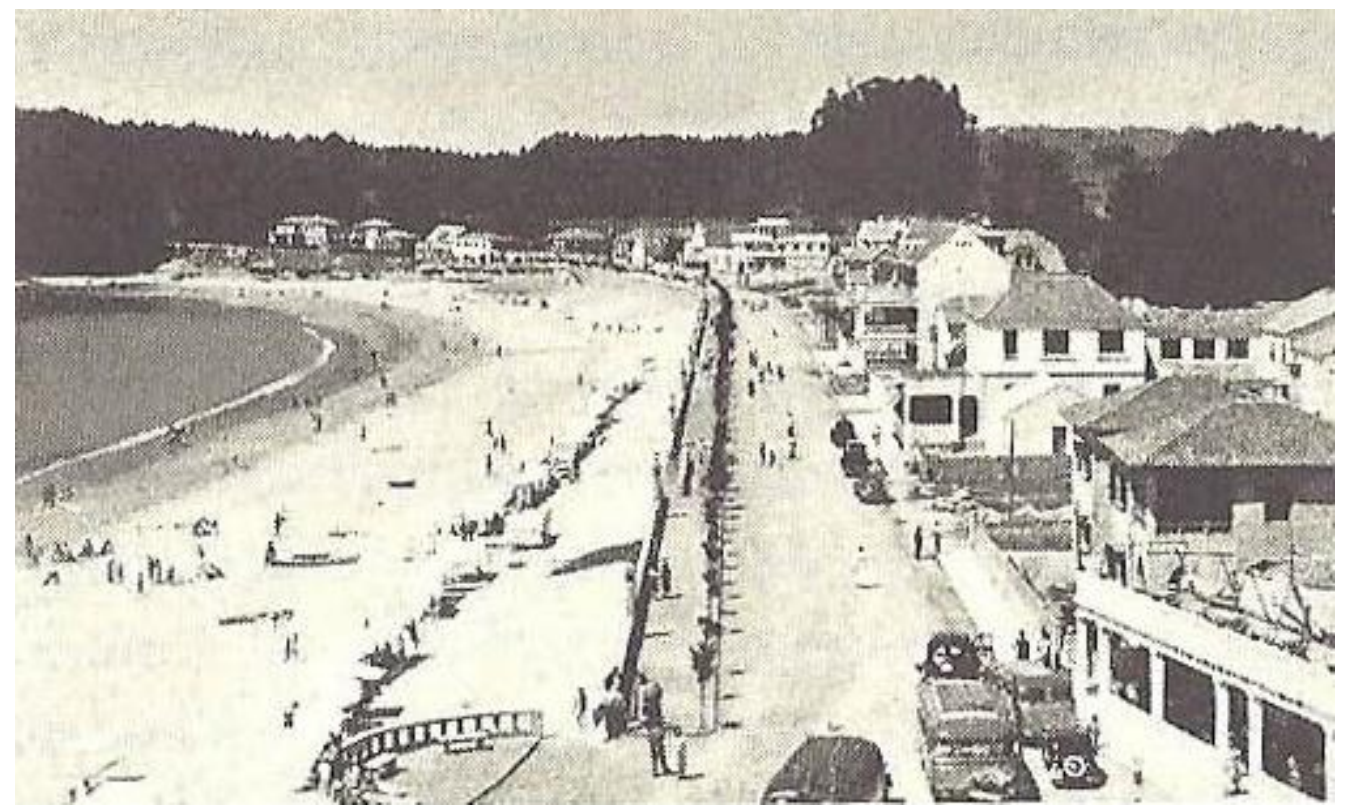

Fuente: De la Sota, 1952.

De la Sota ensayó el tema de la urbanización del litoral con anterioridad a este proyecto en su Urbanización Bahía Bella, en el Mar Menor (Martínez-Arroyo, 2006), en 1965. En la memoria de este proyecto se afirma que hay que transportar una gran masa de gente hasta cierto punto, lo que hace pensar en la prefabricación (industrialización). Añade que la belleza es hoy más grande, tiene otras dimensiones y escalas en relación con el paisaje y, en este caso, a la urbanización (Martínez-Arroyo, 2006). Otros temas que se trataron en Bahía Bella trataban la resolución de problemas funcionales como tener sol, sombra o ver el mar, que también son indicios del interés de De la Sota por el campo expandido de la arquitectura hacia otras disciplinas. En efecto, se trató de entender la arquitectura como paisaje, o como respuesta a un paisaje. De la Sota elude habitualmente hablar sobre arquitectura en sí, como se ha estudiado con el Gimnasio Maravillas, no echando de menos la arquitectura que no tiene, como si tratase de definirla desde sus márgenes. De esta forma, trata la arquitectura como hacía Krauss (1981) con la escultura, entendiéndola desde su campo expandido y desde la contaminación disciplinar que le permite el paisaje.

En Alcudia vuelven a aparecer estos problemas. En su memoria se manifiesta que "según su biología, el hombre tiende a poseer su propio territorio (...) le bastaría con dejar marcas sobre él” (Gallego, 2004, p. 67). Esta frase invita asociar a De la Sota con artistas de Land Art como Michael Heizer citadas por Krauss (1981), y que se encuentra en el campo expandido de la escultura hacia otras disciplinas. En este texto son distintas la doctrinas aludidas y nombradas: la biología, la climatología, el paisaje. 
El tema del paisaje y sus distintas escalas es relevante en el pensamiento y la producción de De la Sota como se ha analizado a lo largo de este artículo. Pero estas viviendas además abordan este tema desde una perspectiva global, en la que la idea del proyecto y su realidad física, abarcan toda la obra en su conjunto. El proyecto trabaja desde la pequeña escala en relación con otros oficios (jardinería, carpintería) y la gran escala relacionada con otras disciplinas (como la geografía o la topografía). En ellas se produce la materialización del interés de De la Sota por las distintas escalas del paisaje, desde la XL del territorio hasta la XS de la flor (Figura 5).

Los dibujos de esta casa manifiestan una capacidad artística envidiable para ensamblar cosas distantes con un único pulso: un espacio geográfico extenso y la sección del territorio la colina (escala $\mathrm{XL}$ ) cuyo pie baña el mar, pero también, por otro lado, todas las hierbas del jardín y las flores (escala XS) (Navarro, 2003).

Figura 5. Dibujo de las viviendas de Alcudia

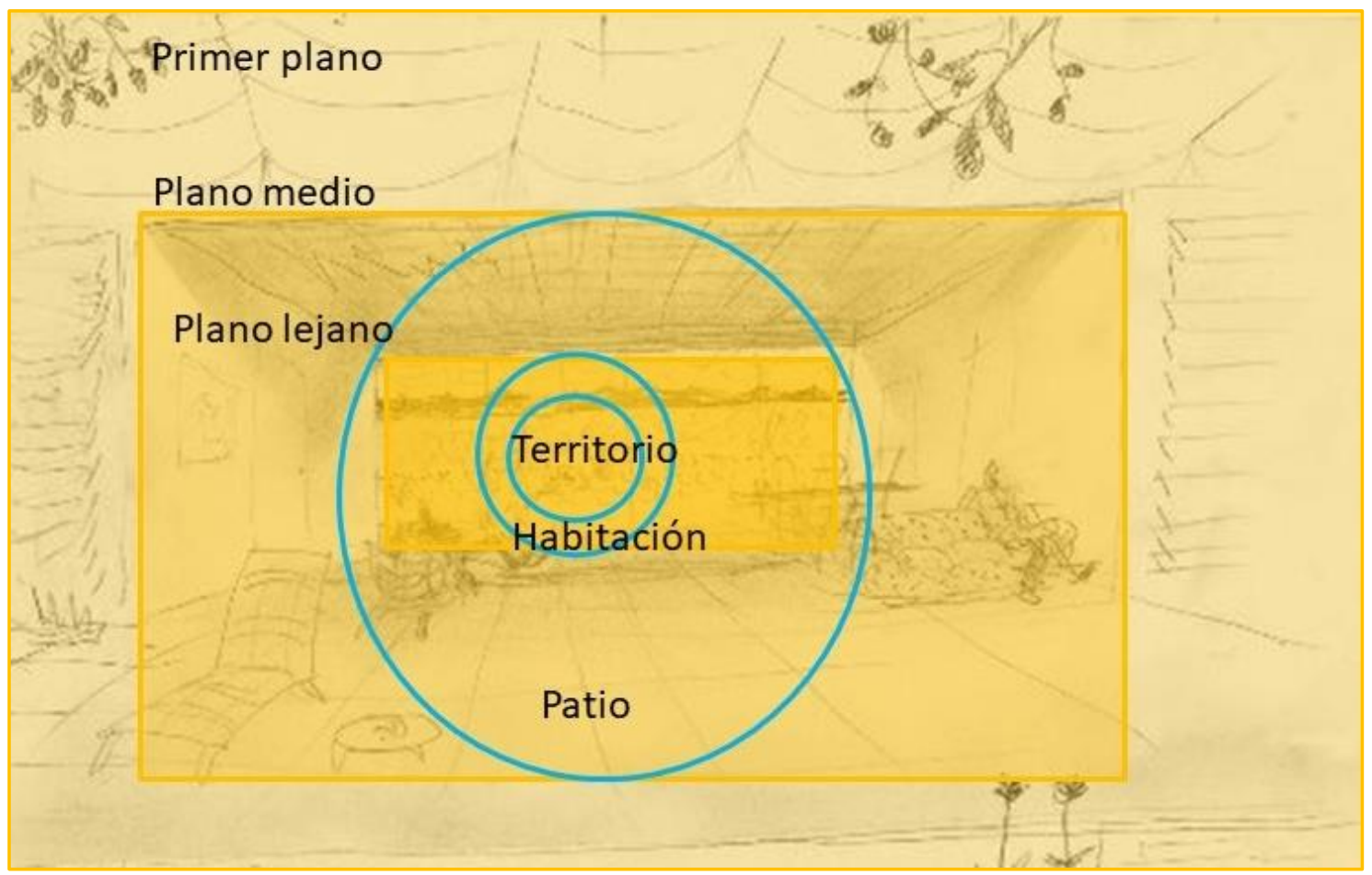

Fuente: Elaboración propia con base en una imagen del Archivo digital de la Fundación Alejandro de la Sota.

Debido a su interés por situar la arquitectura en el campo expandido de otras disciplinas, De la Sota necesita trabajar con una serie de secciones cinéticas (Figura 6) que abarcan desde la montaña al mar. Debido a la complejidad escalar y topográfica del lugar, sus dibujos recuerdan al Team 10 en los que no se puede entender la vivienda aislada de su contexto, sino como parte de una comunidad.

El Team 10 (Risselada,\& Van den Heuvel, 2005).manifestó estas preocupaciones en el Dorm Manifesto y en su texto 1953-1981: In Search of a Utopia of the Present., reflejándolas en el diagrama de Patrick Geddes "La sección del valle" (Figura 6), y proponían la interacción de ambas, aunando lo industrial y lo doméstico, lo natural y lo artificial. 
Figura 6. Sección del valle

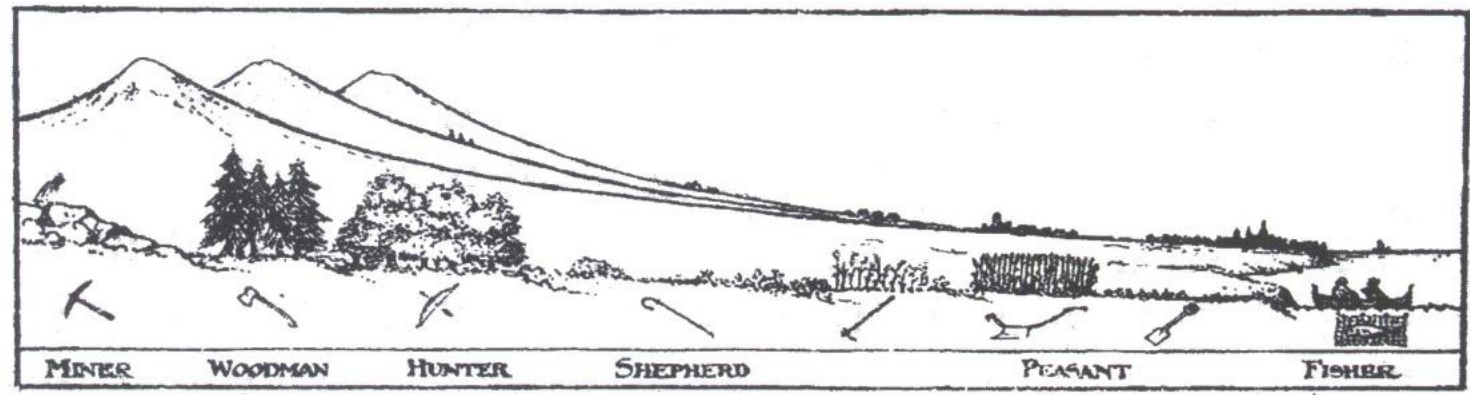

Fuente: Patrick, G., 1906 (Risselada, \& Van den Heuvel, 2005).

De esta forma la sección (Figura 7) se adapta a los distintos gremios humanos o especímenes arquitectónicos según la influencia de las características geográficas, climáticas, topográficas y culturales. En el caso de Alcudia, la vivienda funciona, según sus propias palabras, como periscopio del territorio donde se encuentra: la piscina se construye con agua de ese mar, y las buganvilias acercan la obra a la jardinería, al detalle vegetal de la inmensa escala natural. En texto con el que se abría este artículo (La imagen y el paisaje) De la Sota (1952) afirmaba que, para crear paisajes, antes es necesario acotarlos, prensarlos. En la memoria de las viviendas de Alcudia hay una cita similar: "Viviremos en toda la pequeña parcela que así hemos convertido en la más grande casa" (De la Sota, 1952, p. 28), volviendo a hacer alusión a la idea escalar asociada a las distintas disciplinas. De esta forma se puede asociar esta cita a la de Van Eyck (1990), al que ya se ha mencionado con el Team 10, y que dice que una gran casa es una pequeña ciudad.

Figura 7. Dibujo de las viviendas de Alcudia

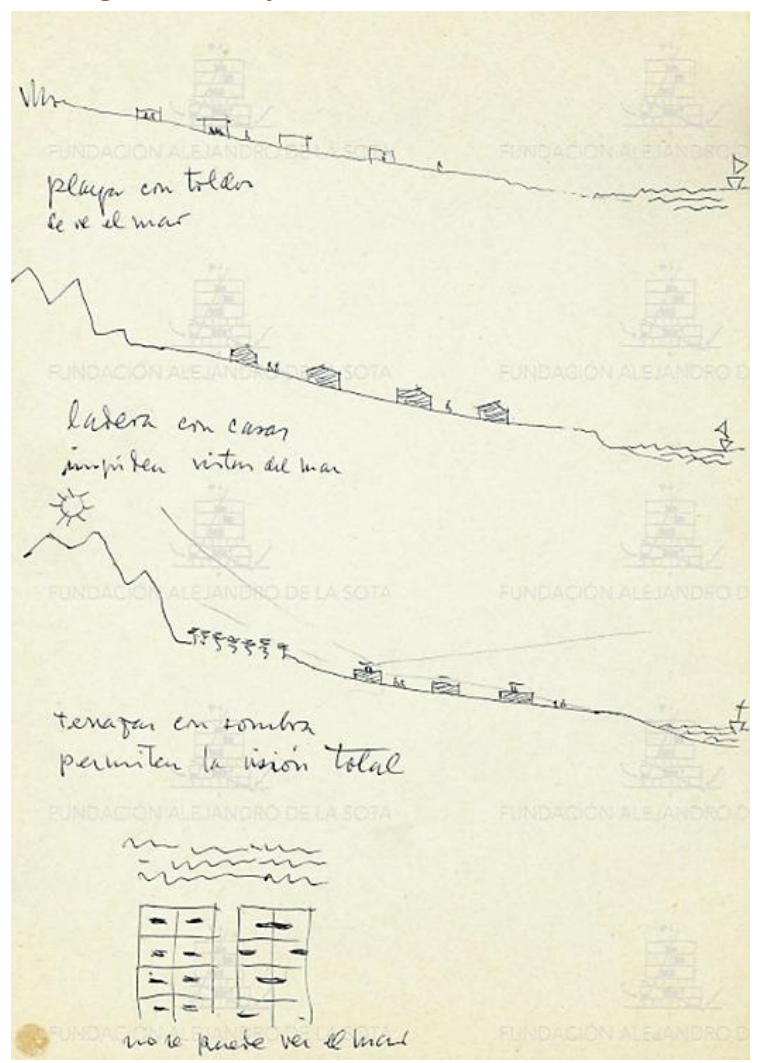

Fuente: Archivo digital de la Fundación Alejandro de la Sota.

ACE, 15 (4.5) CC BY-ND 3.0 ES | UPC Barcelona, España | Arquitectura en el campo expandido. El concepto de

Paisaje en los escritos y en la obra de Alejandro de la Sota. DOI: http://dx.doi.org/10.5821/ace.15.45.8289 
Para Krauss, entre el paisaje y el no-paisaje estaba la escultura, y en estas viviendas de Alcudia está la habitación. Y entre el paisaje y el no-paisaje, en el caso de De la Sota, se encuentra el urbanismo, tanto para el caso de Alcudia como el de Bahía Bella. En el proyecto de Alcudia además podemos comprobar cómo el pensamiento del autor interviene en todas las escalas de la obra incluyendo no solamente el territorio y la vegetación circundante, sino también la de los objetos, muebles u otros elementos domésticos como parte indisoluble de la misma. Navarro (2003) también comenta que el dibujo otorga un amplio sitio a lo que no es arquitectura. Más bien la arquitectura parece ocultarse, desvanecerse y diluirse en las anécdotas. Algunos son elementos tangibles (hamacas, toldos, ropa y complementos estivales como unas gafas de sol) (Figura 8). Otros son intangibles (el carácter mediterráneo y hasta el olor a crema solar), pero no por ello menos fenomenológicos.

Figura 8. Dibujo de las viviendas de Alcudia

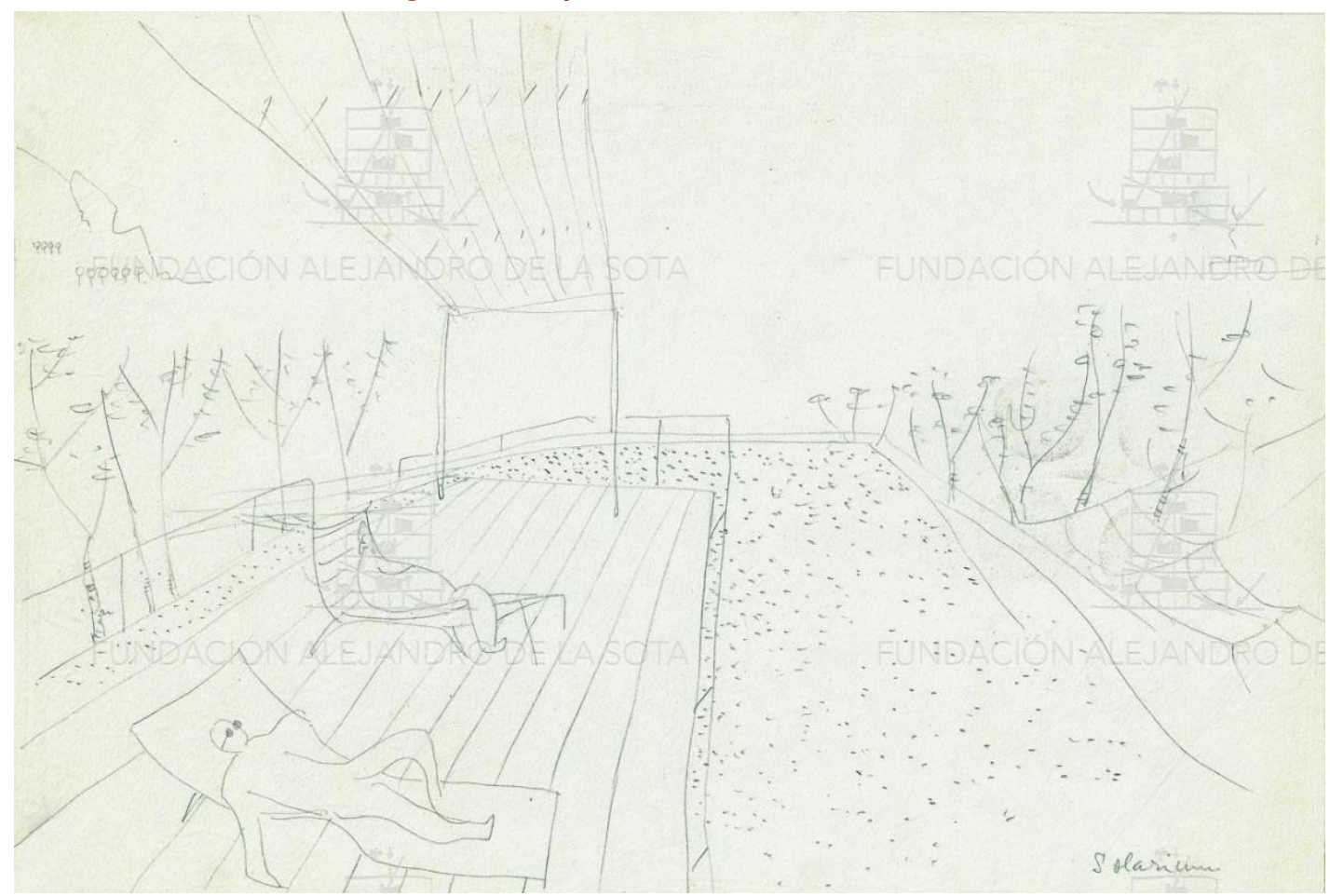

Fuente: Archivo digital de la Fundación Alejandro de la Sota.

En la memoria de Alcudia, De la Sota explica que si el hombre se encierra en su casa pierde la naturaleza. Para atrapar, aunque solo sea una parte de ella, aparece el patio. Para conseguirlo, afirma que no hay nada tan ligado a la naturaleza como la tapia del campesino. Por ello, intentó proyectar una urbanización con más muros, cubiertos por parras, enredaderas y toldos, para que bajo ellos se desarrollase la vida. Otros elementos mediterráneos tradicionales empleados en este proyecto son las pérgolas y la piscina (Figura 8), o más bien alberca, que contiene un fragmento del cercano y salado mar Mediterráneo. Estos elementos se podrían considerar secundarios. Pero en este caso son fundamentales a la hora de analizar el conjunto y entender globalmente la propuesta como una obra integral que se relaciona con el territorio circundante. Estos elementos tradicionales dialogan con los industriales, que enmarcan la obra en su tiempo. Son elementos metálicos que se aprecian en las fichas de planos elaborados con la empresa Robertson, donde aparecen detalles de la estructura, plantas y alzados de los despieces de las chapas metálicas. Como sostiene Navarro al hablar de esta vivienda, "las paredes y el techo son de paneles metálicos fabricados en taller y llevados allí como semillas en volandas" (Navarro, 2003, p. 56). Esta cita vuelve a relacionar la escala del territorio con la del detalle constructivo. Las viviendas de Alcudia, igual que la casa Guzmán, unifican una serie de

ACE, 15 (4.5) CC BY-ND 3.0 ES | UPC Barcelona, España | Arquitectura en el campo expandido. El concepto de 13 Paisaje en los escritos y en la obra de Alejandro de la Sota. DOI: $\underline{\text { http://dx.doi.org/10.5821/ace.15.45.8289 }}$ 
binomios supuestamente antagónicos (artesanía - industria, arquitectura - paisaje, dominio recogimiento). No solamente el interés por lo industrial acerca esta obra a los intereses germanos del momento, sino también el interés por el paisaje. El calvinismo, frente al capitalismo, defiende el paisaje frente al urbanismo, por no imponer el orgullo de la humanidad al de la naturaleza. De la Sota intenta equilibrar ambas doctrinas, jugando con un urbanismo cercano al paisaje, que en su caso además combina tecnología y artesanía. Un urbanismo donde aún se puede leer el paisaje rústico que defendía en "La arquitectura y el paisaje" (De la Sota, 1952).

Todos los aspectos analizados constatan que las viviendas de Alcudia se podrían definir como Gesamtkunstwerk (obra de arte total), teniendo cabida en su diseño desde el estratega territorial, el jardinero leal, y hasta el carpintero industrial. En esta obra el arquitecto ha conseguido pensar, proyectar e incorporar elementos propiamente arquitectónicos, así como aquellos pertenecientes a otras disciplinas. El proyecto se concibe como un todo, contando con componentes esenciales intrínsecos e inseparables a la obra misma y que están al servicio del paisaje integral que suponen estas viviendas en su conjunto, como la vegetación, las vistas que habita o sus elementos constructivos.

\section{Conclusiones}

El bagaje cultural y artístico de Alejandro de la De la Sota y su obra escrita, construida y proyectada, ha permitido el estudio de sus proyectos, en concreto el de Alcudia, desde un punto de vista más amplio y enriquecedor y por las distintas escalas involucradas. Frente a los "arquitectos estrella", De la Sota construye paisajes anónimos, en la línea de la "arquitectura sin arquitectos" defendida por Rudolfsky o en la de una arquitectura sin arquitectura siguiendo la denominación de Krauss, adelantándose a estos grandes teóricos en sus textos.

Figura 9. Ideograma a partir del Diagrama de Krauss. Los textos en negro pertenecen al diagrama original

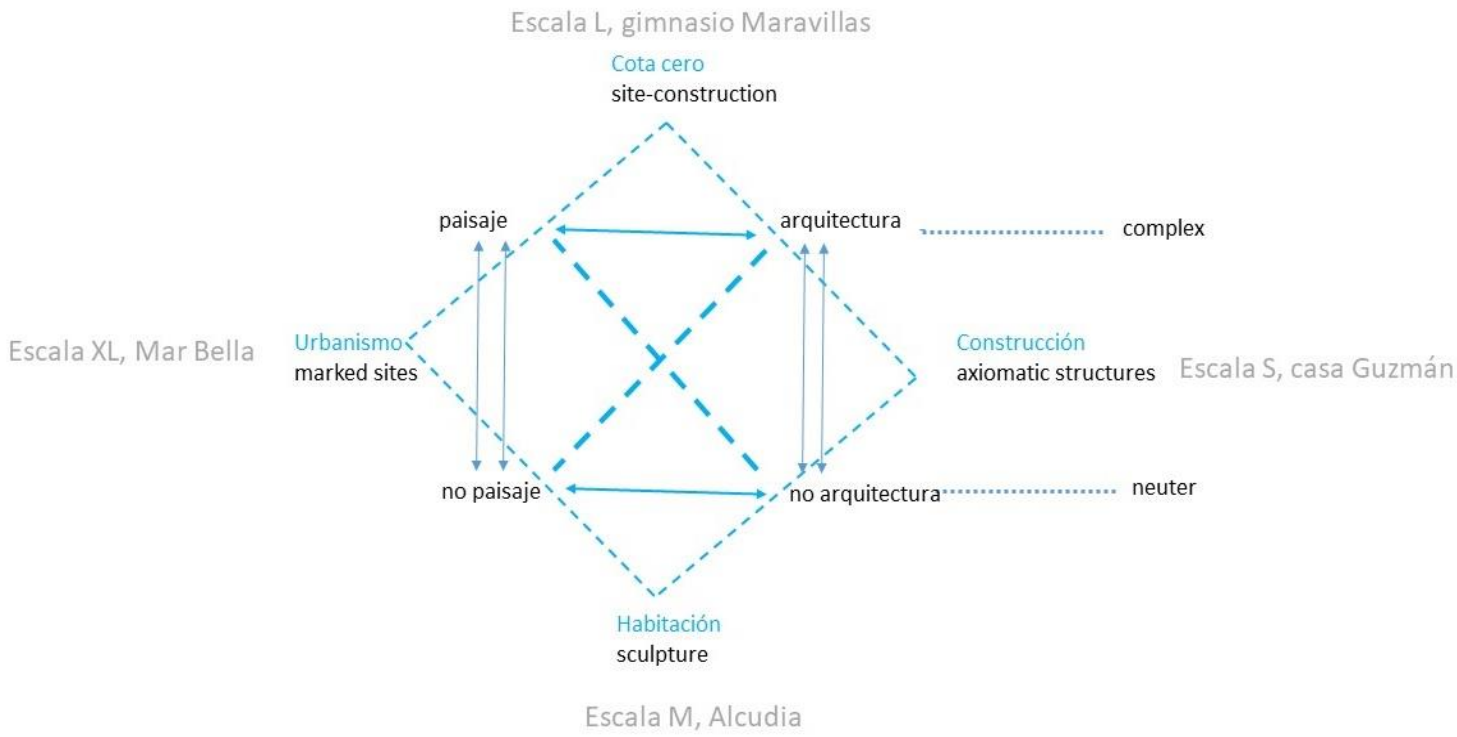

Fuente: Elaboración propia con base en los diagramas de Krauss, 1979.

ACE, 15 (4.5) CC BY-ND 3.0 ES | UPC Barcelona, España | Arquitectura en el campo expandido. El concepto de 14 Paisaje en los escritos y en la obra de Alejandro de la Sota. DOI: http://dx.doi.org/10.5821/ace.15.45.8289 
El paisaje y las distintas escalas (la territorial y la de detalle) con las que trabaja Alejandro de la Sota convierten sus proyectos en obras que pueden considerarse en el campo expandido de la arquitectura hacia el paisaje. Este arquitecto habla de la importancia de estos conceptos en sus textos (que pueden considerarse paisajes escritos) y lo materializa en sus obras (textos construidos). Como creador integral le interesa desde la escala XL del territorio a la XS de la flor. De la Sota maneja en algunos de sus proyectos la escala $\mathrm{XL}$, como un estratega territorial, cercano al ingeniero, seducido por el poder de la infraestructura, de los puentes, los caminos y los muros de contención. En otras obras trabaja con la urbana escala L. La escala M la emplea para acercarnos a la arquitectura y a la habitación. Otros proyectos funcionan a partir de la escala S, pero el arquitecto amplía la obra más allá de esta escala, más allá de sus muros, haciendo que sus obras superen la escala arquitectónica, conquistando el horizonte de la vista.

Si retomamos el diagrama de Krauss comentado al inicio de este artículo, encontramos un campo expandido de posibilidades más allá de campo doctrinal de estas disciplinas (Figura 9). Aparecen nuevas arquitecturas que se encuentran en su campo expandido. De esta forma, las obras que se encuentran entre el paisaje y la arquitectura son aquellas relacionadas con la cota cero, que en nuestro caso de estudio han estado representadas por el gimnasio Maravillas. Las que están entre la arquitectura y la no-arquitectura son las que tienen que ver con lo industrial y con la construcción, como la casa Guzmán. Entre el paisaje y el no-paisaje estaba para Krauss la escultura, y en nuestro caso de estudio está la habitación, singularizada en las viviendas de Alcudia. Y entre el paisaje y el no-paisaje, en el caso de De la Sota se encuentra el urbanismo. Estos conceptos: construcción, habitación, cota cero y urbanismo son imprescindibles para explicar sus proyectos desde la óptica del paisaje y de la arquitectura en el campo expandido. Esta es una posible clasificación de las obras estudiadas, pero podría haber otras, pues la magia de De la Sota es que sus obras no pertenecen a una única disciplina o escala, sino que se mueven fluidamente en su campo expandido.

La anticipación de lo literario a lo constructivo en la obra de De la Sota, relacionada con el paisaje, parece dar indicios de que primero se exploró el conocimiento y después se pasó a la acción sobre el propio paisaje. De la Sota también se adelantó en sus críticas a otros importantes teóricos y pioneros del estudio del paisaje y era conocedor de lo que se estaba haciendo en su momento al otro lado del mundo. Sus obras analizadas demuestran que las distintas escalas involucradas (la territorial, la del detalle constructivo) influyeron en la producción de este creador integral, haciendo de ella una obra total que supera lo arquitectónico, situándose en su campo expandido. Como se ha visto a lo largo de este artículo, De la Sota también da en sus textos referencia a obras de Neutra que estaban siendo realizadas en esos mismos años.

Alejandro de la Sota recurre al paisaje como material de concepción y construcción de sus proyectos, como cartografía a emplear en su urbanización, como fuente de observación y habitación y como cota cero en la que fluctúan y con la que dialogan sus edificios. Los elementos construidos de sus viviendas reflejan la relación con la industria germana del momento, tamizados por el filtro de la artesanía ibérica, más próxima a los materiales naturales del entorno. El concepto moderno de industrialización se importó a una España pobre y poco industrializada, pero con una artesanía todavía viva. El gusto por lo industrial acerca esta obra a los intereses germanos del momento, al Deutscher Werkbund, así como su interés por el paisaje.

Su obra es catalizadora del paisaje y del urbanismo que rodea a sus proyectos, como arquitectura en el campo expandido; es decir, que va más allá de la propia disciplina arquitectónica hacia otras disciplinas como el paisaje o la geografía, la geográfica y su cota cero, abarcando escalas que superan la arquitectónica.

Como conclusión, se deduce que la obra de De la Sota supera lo arquitectónico y emplea el pasaje como elemento definidor y desencadenante de sus proyectos, consiguiendo que el proyecto salga

ACE, 15 (4.5) CC BY-ND 3.0 ES | UPC Barcelona, España | Arquitectura en el campo expandido. El concepto de 15 Paisaje en los escritos y en la obra de Alejandro de la Sota. DOI: http://dx.doi.org/10.5821/ace.15.45.8289 
del propio paisaje, en lugar de estar impuesto a él, gracias a la construcción con elementos del propio paisaje y a la habitación de su horizonte.

\section{Agradecimientos}

Se agradece a la Fundación Alejandro de la Sota por su colaboración para la elaboración de este artículo y a las personas que han evaluado el trabajo y que han ayudado a su perfeccionamiento.

Conflicto de intereses: La autora declara que no hay conflicto de intereses.

\section{Bibliografía}

Ábalos, I. (2005). La belleza en el siglo XXI. En CIRCO (Vol. 128). Recuperado de https://docplayer.es/25331018-Circo-la-belleza-en-el-siglo-xxi-inaki-abalos-jaia-lore-artean.html

Ábalos, I., Llinas, J., \& Puente, M. (2009). Alejandro de la Sota. Fundación Caja de Arquitectos. Recuperado de https://www.letrasavila.com/es/libros/alejandro-de-la-sota_ATE0023648

Baldellou, M. Á. (1976). Alejandro de la Sota. Servicio de publicaciones del Ministerio de Educación y Ciencia. Recuperado de http://oa.upm.es/48302/

Baldellou, M. Á. (1997). Gimnasio maravillas, Madrid, 1960-1962: Alejandro de la Sota. Colegio de Arquitectos de Almería, España. Recuperado de http://oa.upm.es/48197/

Baldellou, M. (2006). Alejandro de la Sota. Madrid, España: Ayuntamiento de Madrid.

Couceiro, T. (2007). Alejandro de la Sota. Gimnasio del Colegio Maravillas. Fundación Alejandro de la Sota.

Eisenman, P. (2008). Siete puntos. Minerva: Revista del Círculo de Bellas Artes 8, 30-32. Recuperado de https://cbamadrid.es/revistaminerva/articulo.php?id=244

Gallego, M. (2004). Viviendas en Alcúdia, Mallorca 1984. Ministerio de vivienda. Recuperado de http://www.editorialrueda.es/tienda-online/Catalog/show/viviendas-en-alcudia-mallorca-alejandrode-la-sota-138

García-Hípola, M. (2014). Edificios con escala de paisaje. Agadir de Oma y Yokohama de Foa. ACE; Architecture, City and Environment, 9(26), 53-68. DOI: https://doi.org/10.5821/ace.9.26.3562

Gilpin, W. (1792). Three Essays: On Picturesque Beauty; On Picturesque Travel; and On Sketching Landscape: To which is Added a Poem, on Landscape Painting. Blamire.

Hofmann, W. (2007). Las partes y el todo. Texto del catálogo de la exposición: La abstracción del paisaje. Del romanticismo nórdico al expresionismo abstracto. Madrid, España: Fundación Juan March.

Kimball, R. (1987). The Collected Essays and Criticism, by Clement Greenberg, edited by John O'Brian. Commentary Magazine. Recuperado de https://www.commentarymagazine.com/articles/rogerkimball/the-collected-essays-and-criticism-by-clement-greenberg-edited-by-john-obrian/

Koolhaas, R. (1998). ITT Student Competition Address, Illinois Institute of Technology. Chicago: College of Architecture.

Krauss, R. (1979). Sculpture in the Expanded Field. The MIT Press, 8, 30-44. Recuperado de http://www.onedaysculpture.org.nz/assets/images/reading/Krauss.pdf

Krauss, R. (1981). Passages in Modern Sculpture. New York: The Viking Press. https://monoskop.org/images/d/d0/Krauss_Rosalind_E_Passages_in_Modern_Sculpture.pdf

ACE, 15 (4.5) CC BY-ND 3.0 ES | UPC Barcelona, España | Arquitectura en el campo expandido. El concepto de 16 Paisaje en los escritos y en la obra de Alejandro de la Sota. DOI: http://dx.doi.org/10.5821/ace.15.45.8289 
Kwinter, S. (2002), Architecture of Time: Towards a Theory of the Event in Modernist Culture. Cambridge: MIT Press. http://www.mom.arq.ufmg.br/mom/02 arq interface/6a aula/kwinter chap1.pdf

Holl, S. (1989), Anchoring. New York, EE.UU.: Princeton Architectural Press.

Maderuelo, J. (1996). Paisajes descritos. Un paseo por la literatura. En Actas. El paisaje. Arte y Naturaleza. Huesca. Javier Maderuelo (ed.), 109-135.

Martínez-Arroyo, R. (2006) Alejandro de la Sota. Cuatro agrupaciones de vivienda: Mar Menor, Santander, Calle Velázquez, Alcudia. Toledo: Demarcación de Toledo COACM. Recuperado de https://www.worldcat.org/title/alejandro-de-la-sota-cuatro-agrupaciones-de-vivienda-mar-menorsantander-calle-velazquez-alcudia/oclc/804592528

Puente, M. (ed.) (2002). Alejandro de la Sota: Escritos, conversaciones, conferencias. Barcelona: Editorial GG. Recuperado de https://www.digitaliapublishing.com/a/41345/alejandro-de-la-sota--escritos--conversaciones--conferencias

Smithson, R. (1973). Frederic Law Olmsted and the dialectical landscape. Art Forum. New York University Press. Recuperado de https://www.artforum.com/print/197302/frederick-law-olmstedand-the-dialectical-landscape-36282

Sota, A. (1956). Arquitectura y naturaleza. Conferencia pronunciada en un Curso de Jardinería y Paisaje. Publicada originalmente en Escuela Técnica Superior de Arquitectura. Tomada de Puente, M (ed.) (2002). Escritos, conversaciones, conferencias. Barcelona: Editorial GG.

De la Sota, A. (1954). Algo sobre paisajes y jardines. En Cedro 4. Arquitectura y Naturaleza. Conferencia pronunciada en el curso de Jardinería y Paisaje. Madrid, COAM.

De la Sota, A. (1952). La arquitectura y el paisaje. Revista Nacional de Arquitectura 128, 34-38. Recuperado de https://www.coam.org/es/fundacion/biblioteca/revista-arquitectura-100anios/etapa-1946-1958/revista-nacional-arquitectura-n128-Agosto-1952

Navarro-Baldeweg, J. (2003). El horizonte en la mano / discurso del académico electo Juan NavarroBaldeweg, leído en el acto de su recepción pública el día 19 de octubre de 2003, y contestación del Excmo. Sr. D. Joaquín Vaquero Turcios. Alicante: Biblioteca Virtual Miguel de Cervantes. Recuperado de http://data.cervantesvirtual.com/manifestation/249979

Navarro-Baldeweg, J. (1997). Construir y habitar. Arquitectura Viva, 168, 30-32. Recuperado de https://arquitecturaviva.com/articulos/construir-y-habitar

Price, U. (1794). An Essay on the Picturesque, as Compared with the Sublime and the Beautiful. And, on the Use of Studying Pictures, for the Purpose of Improving Real Landscape. London, Reino Unido: Cambridge University Press.

Rudofsky, B. (1964). Architecture Without Architects: An Introduction to Non-Pedigreed Architecture. New York: The Museum of Modern Art. Recuperado de https://www.moma.org/documents/moma_catalogue_3459_300062280.pdf

Risselada, M., \& Van den Heuvel, D. (2005). Team 10: 1953-81, In Search of a Utopia of the Present. Rotterdam, Paises Bajos: NAi Publishers.

Van Eyck, A (1990). El interior del tiempo y otros escritos. Madrid, España: Circo.

Vidler, A. (1988). Después del fin de la línea. Revista Arquitectura 270, 92-104. Recuperado de https://www.coam.org/media/Default\%20Files/fundacion/biblioteca/revista-arquitectura-100/19871990/docs/revista-articulos/revista-arquitectura-1988-n270-pag92-104.pdf

ACE, 15 (4.5) CC BY-ND 3.0 ES | UPC Barcelona, España | Arquitectura en el campo expandido. El concepto de

Paisaje en los escritos y en la obra de Alejandro de la Sota. DOI: http://dx.doi.org/10.5821/ace.15.45.8289 